\title{
Evaluation of Nigerian Waxy Crude Oil Using Rheological Models
}

\author{
Igwilo K.C. ${ }^{1}$, Anawe P. A.L. ${ }^{2}$, Orodu O.D ${ }^{3}$, Okolie T.A ${ }^{4}$, Okechukwu L.T ${ }^{5}$. \\ 1,2,3,4 Covenant University, Ota, Ogun State, Nigeria \\ 5 Federal University of Technology, Owerri, Nigeria
}

\begin{abstract}
This paper evaluates Nigerian Waxy Crude Oil using Bingham Plastic model and Power Law model. Laboratory measurements on rheology were carried out on the sample as per API standard at temperatures of $30^{\circ} \mathrm{C}$ and $50^{\circ} \mathrm{C}$. The obtained data of shear rate and shear stress were regressed and plotted. The Bingham Plastic model gave the values of yield stress and the regression coefficient as $0.673 \mathrm{lbs} / 100 \mathrm{ft}{ }^{2}$ and 0.9996 at the temperatures of $30^{\circ} \mathrm{C} ; 0.622 \mathrm{lbs} / 100 \mathrm{ft}^{2}$ and 0.9986 at the temperature of $50^{\circ} \mathrm{C}$. Also, the Power Law model gave zero yield stress and regression coefficient of 0.9737 and 0.9884 at both temperatures. From the result, Nigerian Waxy Crude Oil is more adequately predicted by Bingham Plastic model because of the exhibition of Plastic behavior of a higher regression coefficient.
\end{abstract}

Keywords: Nigerian Waxy Crude, Bingham Plastic model, Power Law model, Regression coefficient and Yield stress.

\section{INTRODUCTION}

Waxy crude oils are those which deposit organic crystals on cooling. Deposition can occur both in subsurface and surface production facilities. There are two categories of waxy crudes, namely (1) paraffins and (2) asphaltenes ${ }^{1}$. The problem of paraffin asphaltenes deposition can vary from very minor to extremely severe and affect both the production history and economics of production operations adversely. The severity of paraffin deposition depends predominantly on the composition (wax content) of the crude oil, the cloud point, the pour point, the rate of evolution of gas, well depth, formation temperature, the ambient and operating temperatures, pressure drop, previous shear history, pipe roughness and production practices.

Cloud-point is the temperature at which a haze forms in clear oil which is being cooled. For a crude oil, it is the temperature at which paraffin particles begin to precipitate out of solution. Generally, depending on the flow regime (laminar), wax deposition begins to occur on any surface referred to as cold spot whose temperature is below this critical cloud-point and that of the bulk oil. The pour-point is defined as the temperature below which the oil ceases to flow (pour). The pour-point is usually 10$20^{\circ} \mathrm{F}$ lower than the cloud-point. In the case of asphaltene deposition, the severity depends mainly on the composition of the crude oil, operating pressure and temperature and the enhanced oil recovery methods. It is known in both cases that the severity of the problem increases with the age of the oil field. Thus the term waxy crude is used to embrace both kinds of organic deposition, of the two kinds of deposition, paraffin deposition is the most widespread and more easily handled while asphaltene deposition is much more difficult to treat because of the complex depositional relationship between the crude oil composition, pressure and temperature.

Wax is a commonly occurring component of crude oil. It is generally characterized as consisting of large n-paraffins that are solid at room temperature when isolated. Yet, they are soluble in the crude oil mixture at elevated temperatures. Waxy crude oils are crude oils with relatively high amount of wax suspended in them ${ }^{2}$.

Many Crude Oils throughout the world contain significant quantities of wax, which can crystallize during production, transportation and storage of the oil, which may lead to flow restriction and plug the pipelines as shown. The presence of long-chain saturated alkanes in crude oil can lead to relentless problems associated with wax precipitation and deposition in petroleum transport pipelines and 
processing equipment ${ }^{3}$. Furthermore, the presence of solid waxes in oil systems may affect the prediction and evaluation of the flow properties.

Waxes distribute differently from oil fields to oil fields, and they have a broad molecular weight distribution ranging approximately from 10 to 100 carbons or even higher. Waxes are classified as straight-chain n-alkanes/paraffin (C20-C40), and microcrystalline consisting of high molecular weight isoparaffins and cycloparaffin.

Some types of waxes crystallize as large needles and plates such as paraffins whereas other types like microcrystalline is termed amorphous wax, which consist of branched and cyclic hydrocarbons. In general, Crude oils contain not only n-paraffins but also considerable amounts of isoparaffins and cyclic compounds. It is found that n-paraffin dissolved in organic solvents display a sharp transition in gel strength at the pour point, whereas by addition of isoparaffins, the buildup in gel strength as a function of temperature is much more gradual, because increasing isoparaffin fraction facilitates the formation of amorphous wax solids ${ }^{3}$.

At high temperatures, waxes are in the molten state, and crude oils normally behave like Newtonian fluids ${ }^{4}$. If waxy crude is allowed to cool to the temperatures below the Wax Appearance Temperature (WAT), wax will precipitate, agglomerate and entrap the liquid oil into its structure, and the crude will become a two-phase dispersion with wax solid particles dispersed in the liquid hydrocarbons. Precipitation of wax significantly increases crude viscosity and will gradually change the flow properties of the crude from Newtonian to non-Newtonian behavior. The crude begins to show nonNewtonian flow behavior at a temperature called the abnormal point which is generally a few degree Celsius below the WAT.

\section{Rheological Models}

A rheological model describes the flow behavior of fluid by expressing a mathematical relationship between shear rate and shear stress.

Bingham Plastic model: This model describes some fluids that exhibit a plastic behavior distinguished from Newtonian fluids in that they require a yield stress to initiate flow. No bulk movement of the fluid occurs until the applied force exceeds the yield stress. The yield stress is commonly referred to as the yield point and it is that point at which the range of reversible elastic deformation ends and range of irreversible deformation or viscoelastic-viscous flow begins. The shear stress-shear rate relationship for this model is given by:

$\tau=\tau_{y}+\mu_{p} \gamma$

Where $\tau_{\mathrm{y}}$ is the yield point and $\mu_{\mathrm{p}}$ is the plastic viscosity.

Power Law model: This model describes fluids that falls between the behaviors described by the Newtonian model and the Bingham Plastic model. This behavior is classified as either pseudo plastic or dilatant. The relationship between shear stress and shear rate for either pseudo plastic or dilatant fluids is defined by the Power Law Mathematical Model.

$\tau=K \gamma^{n}$

Where $\mathrm{K}$ is the consistency factor (also called viscosity) and $\mathrm{n}$ is the power law index or flow behavior index and indicates the degree of non-Newtonian behavior. For $\mathrm{n}<1$ the fluid is pseudo plastic, whereas for $n>1$ the fluid is dilatant. If $n=1$, this model is reduced to the Newtonian model.

\section{Materials AND Methods}

A crude oil sample of specific gravity 0.91 was taken and homogenized to ensure that the crude oil's physical properties are the same anywhere the sample is taken for the measurements. The rheological laboratory measurements were taken at $30^{\circ} \mathrm{C}$ and $50^{\circ} \mathrm{C}$ respectively. This was followed by Wax content determination by precipitation method ${ }^{5}$. The crude oil sample is dissolved in n-pentane and stirred during 30 minutes. Acetone (acetone/n-pentane ratio 3:1) is added to the mixture and cooled down to $253 \mathrm{~K}$ for 24 hours. The solid phase present in the oil is separated by filtration in a Buchner funnel using a glass microfiber. 


\section{Results AND Discussion}

\subsection{Rheological Models}

Table1. Bingham model calculations

\begin{tabular}{|c|c|c|c|c|c|}
\hline \multicolumn{2}{|c|}{ Shear Rate, $\gamma$} & \multicolumn{2}{|c|}{$50^{\circ} \mathrm{C}$} & \multicolumn{2}{c|}{$30^{\circ} \mathrm{C}$} \\
\hline RPM & $\mathrm{s}^{-1}$ & Dial Reading & $\tau, \mathrm{Pa}$ & Dial Reading & $\tau, \mathrm{Pa}$ \\
\hline 600 & 1022 & 33 & 16.87 & 67 & 34.25 \\
\hline 300 & 511 & 18 & 9.20 & 35 & 17.89 \\
\hline 200 & 341 & 12 & 6.14 & 24 & 12.27 \\
\hline 100 & 170 & 7 & 3.58 & 12 & 6.14 \\
\hline 60 & 102 & 4 & 2.05 & 8 & 4.09 \\
\hline 30 & 51 & 3 & 1.53 & 4 & 2.05 \\
\hline 6 & 10 & 1 & 0.51 & 2 & 1.02 \\
\hline
\end{tabular}

Table2. Power Law model calculations

\begin{tabular}{|c|c|c|}
\hline \multirow{2}{*}{$\mathrm{s}^{-1}$} & $50^{\circ} \mathrm{C}$ & $30^{\circ} \mathrm{C}$ \\
\cline { 2 - 3 } & $\operatorname{Ln} \tau, \mathrm{Pa}$ & $\operatorname{Ln} \tau, \mathrm{Pa}$ \\
\hline 6.93 & 2.83 & 3.53 \\
\hline 6.24 & 2.22 & 2.88 \\
\hline 5.83 & 1.81 & 2.51 \\
\hline 5.14 & 1.28 & 1.81 \\
\hline 4.62 & 0.72 & 1.41 \\
\hline 3.93 & 0.43 & 0.72 \\
\hline 2.30 & -0.67 & 0.02 \\
\hline
\end{tabular}

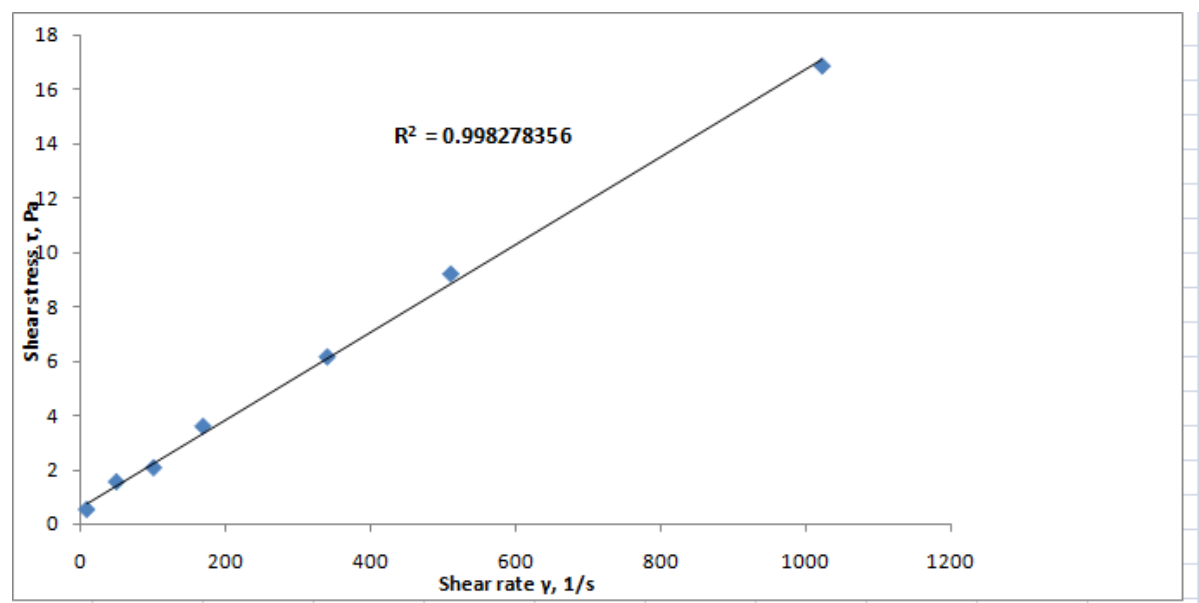

Fig1. Bingham model at $50^{\circ} \mathrm{C}$

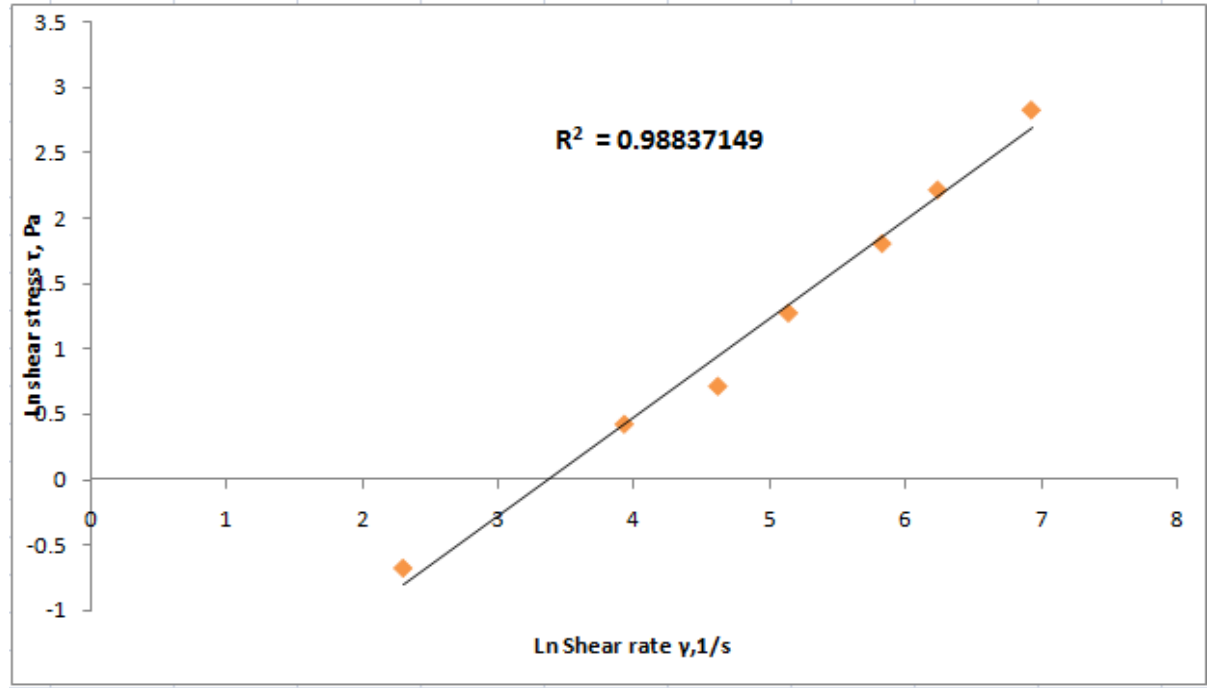

Fig2. Power law model at $50^{\circ} \mathrm{C}$ 
Igwilo K.C. et al.

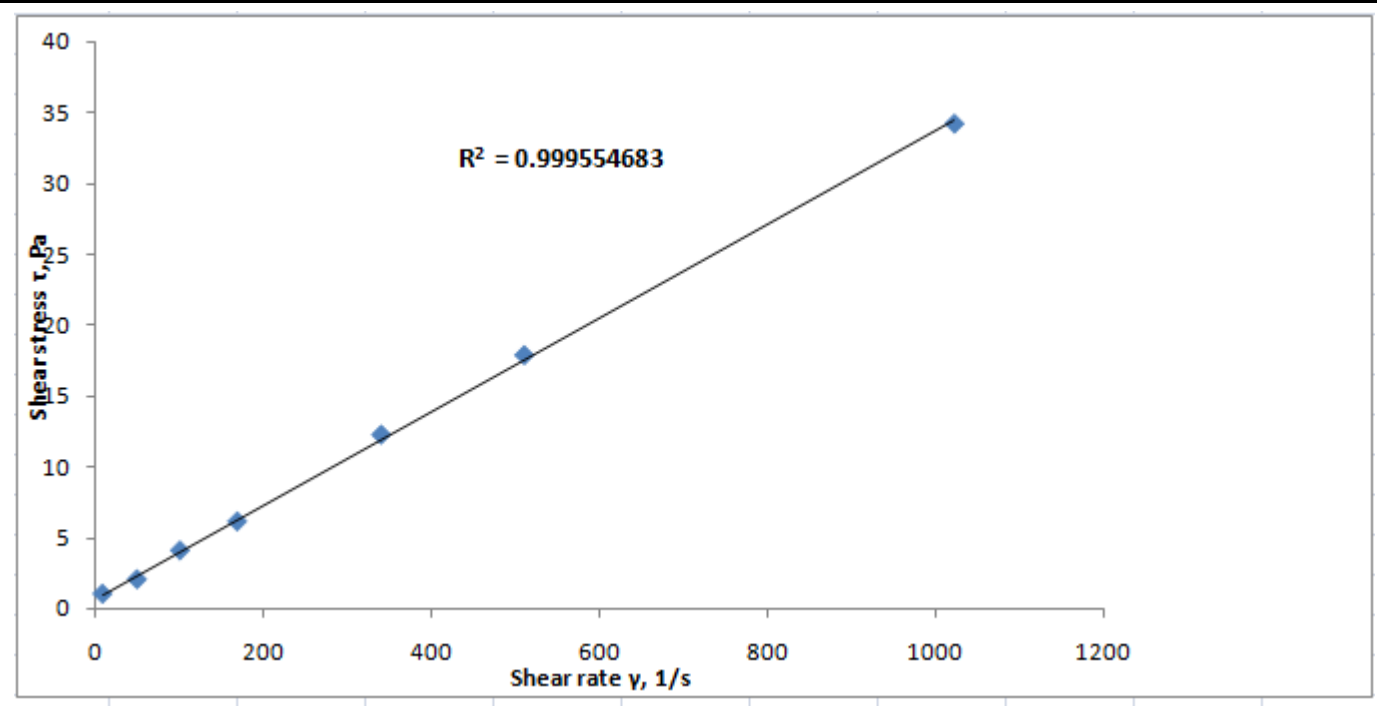

Fig3. Bingham model at $30^{\circ} \mathrm{C}$

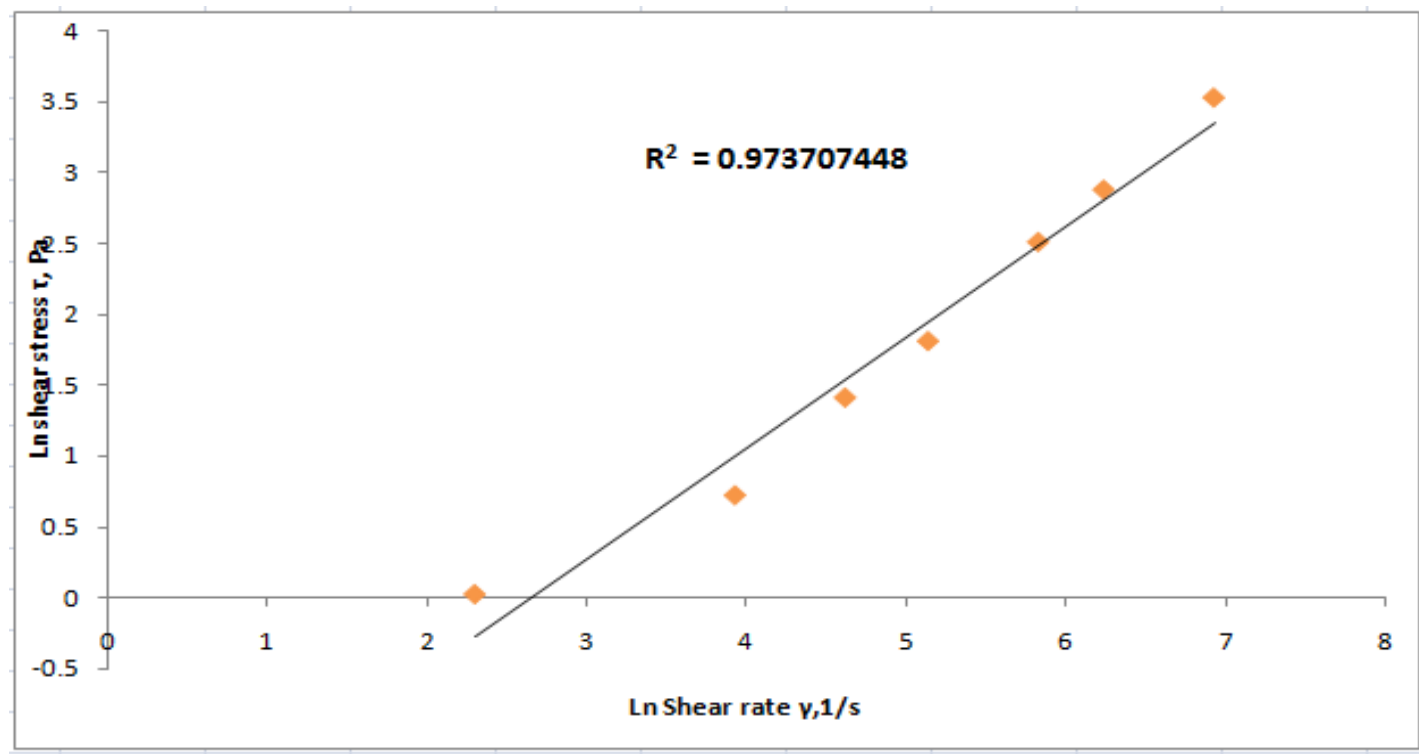

Fig4. Power law model at $30^{\circ} \mathrm{C}$

From figures 1 to 4, Bingham Plastic model gave the values of 0.9996 and 0.9983 as Regression Coefficient at $30^{\circ} \mathrm{C}$ and at $50^{\circ} \mathrm{C}$ compared with the values given by Power Law model of Regression Coefficient of 0.9737 and 0.9884 at both temperatures. Although, the results given by the two models were close.

Bingham model predicted very adequately the flow behavior of the crude oil sample over the tested range of shear rates. This observation suggests Nigerian Waxy crude oil exhibits plastic behavior. Table 3 reports the higher regression coefficient, $\mathrm{R}^{2}$, for the Bingham model.

Table3. Rheological Parameters and Correlation Coefficients of models

\begin{tabular}{|c|c|c|c|c|c|c|}
\hline Temperature ${ }^{\circ} \mathrm{C}$ & \multicolumn{3}{|c|}{ Bingham Plastic } & \multicolumn{3}{c|}{ Power Law } \\
\cline { 2 - 7 } & $\tau_{y}$ & $\mu_{p}$ & $\mathrm{R}^{2}$ & $\mathrm{~K}$ & $\mathrm{n}$ & $\mathrm{R}^{2}$ \\
\hline 30 & 0.673 & 0.033 & 0.9996 & 0.126 & 0.78 & 0.9737 \\
\hline 50 & 0.622 & 0.016 & 0.9983 & 0.079 & 0.75 & 0.9884 \\
\hline
\end{tabular}

The rheological characteristics of materials form a continuous spectrum of behavior, ranging from the perfectly elastic Hooke an solid at one extreme, to that of purely viscous Newtonian fluid at the other.

\section{Conclusion}

From the Plots, Bingham Plastic model describes the Nigerian Waxy Crude oil better than the Power law model in terms of the Regression Coefficient. 


\section{REFERENCES}

[1] Strubhar, M.K., Blackburn, J.S. and Lee, J.W. (1972): Production Operations Course II - Well Diagnosis, SPE - AIME Dallas Texas p.20.

[2] Wardhaugh L.T., Boger D.V. and Tonner S.P. (1988): Rheology of Waxy Crude Oils, SPE 17625.

[3] Vistin R.F.G., et al. (2005): Rheological Behavior and Structural Interpretation of Waxy Crude Oil Gels.

[4] Shadi Hasan (2007): Rheology of Heavy Crude Oil and Viscosity Reduction for Pipeline Transportation.

[5] Coto B., Martos C., Pena J.L., Espada J.J., and Robustillo, M.D. (2008): A New Method for the Determination of Wax Precipitation from non-diluted crude oils by fractional precipitation. Fuel, 87, 2090-2094.

\section{AUTHORS' BIOGRAPHY}

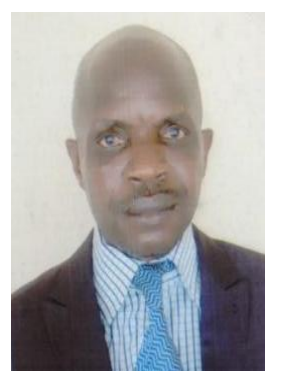

Dr Igwilo Kevin Chinwuba, holds a bachelor's degree in Petroleum Engineering, master's degree and doctorate degree also in Petroleum Engineering. He is an Assistant Professor, Federal University of Technology, Owerri, Nigeria; a Visiting Lecturer, African University of Science and Technology, Abuja, currently doing his Sabbatical Leave with Covenant University, Nigeria. Kevin has over 20years oilfield working experience as a Drilling Engineer, Drilling Fluids Engineer/Instructor, Mud Logger, Wellhead Engineer, Production Chemist and a Well Site Petroleum Engineer with Schlumberger, Baker Hughes, Shell, Interdrill and Vetco Gray. He has worked in different parts of the world : Nigeria, Ghana, Guinea, Qatar and UK. He authored/co-authored over 25 Journal Publications and 1 text book on drilling fluids. And review articles for publication in journals. He is the Managing Director of Ken Pam Mud School.

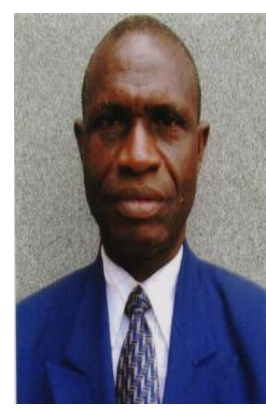

Dr Anawe, Paul Lucky, is currently an Associate Professor and currently the Acting Head of Department, Petroleum Engineering at Covenant University, Nigeria. He holds a bachelor's degree in Chemical Engineering, master's degree also in Chemical Engineering, doctorate degree in Lubrication Engineering (Azerbaidjan State Oil and Gas Academy, USSR). Paul was the Liquefied Petroleum Gas Manager in 1991 with elf Petroleum, Chemical Division in Nigeria. $\mathrm{He}$ is a registered engineer in Nigeria (R. Eng; COREN). He has authored/coauthored over 42 journal publications and articles. His current research interest is on drilling fluids, various methods of crude oil treatment, Petroleum Refining/Petrochemical issues, Corrosion issues in the oil and gas industry.

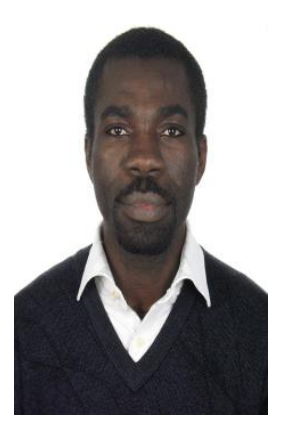

Dr. Oyinkepreye David Orodu, has varied Oil \& Gas industry experience spanning field operations and academia. He has authored/ co-authored over 40 publications including SPE papers and journal articles, and reviews articles for publication in journals. Preye holds a bachelor's degree in Chemical Engineering and master's and doctorate degree in Petroleum Engineering. He is currently the Postgraduate Co-ordinator, Petroleum Engineering Department at Covenant University, Nigeria. His areas of core competence are reservoir engineering and characterisation, and petroleum production economics. He had undertaken reservoir studies of oilfields in the Far-East as a research assistant and his current research interest includes "decision analysis and stochastic modeling of optimal well utilization for multi- well systems", " characterization and modeling of flow units" and" Niger Delta Heavy Oil Producibility Evaluation (HOPE)". Preye is an SPE member and a registered engineer (R.Eng., COREN) in Nigeria. 